\title{
Acute myocardial injury after scorpion (Hottentotta tamulus) sting
}

\author{
R M U K B Ratnayake ${ }^{1}$, T Kumanan ${ }^{1}$, G Selvaratnam ${ }^{1}$ \\ Ceylon Medical Journal 2016; 61: 86-87～～DOI: http://doi.org/10.4038/cmj.v61i2.8293
}

\section{Introduction}

White scorpion (Hottentotta tamulus), also known in India as the 'red scorpion', was not sighted in Sri Lanka until 1990, leading to the belief that the species migrated to Jaffna peninsula with the movement of Indian Peace Keeping Force (IPKF) in 1987 with their luggage. There has been a gradual increase in cases reported with Hottentotta tamulus stings since the end of civil war in 2009 with confirmed 22 hospital admissions (out of 78 stings by scorpions) in 2013 [1]. White scorpion toxin contains polypeptides which cause sympathetic and parasympathetic stimulation leading to signs and symptoms ranging from swelling and severe local pain along the affected dermatome to an 'autonomic storm' causing tachy- or bradycardia, hypo- or hypertension, priapism, excessive salivation, pulmonary oedema and rarely myocarditis.

\section{Case report}

A 34-year old farmer came to the emergency unit of the Teaching Hospital, Jaffna after a white scorpion (Hottentotta tamulus) sting on the dorsum of the foot an hour earlier. On admission he had severe pain and swelling at the sting site with giddiness and profuse sweating. On examination he was tachycardic with a blood pressure of 180/110 mm Hg. The patient was started on oral prazosin hydrochloride $0.5 \mathrm{mg}$ three hourly. Oral acetaminophen, lignocaine $0.5 \mathrm{mg}$ subcutaneous injections, and ice packs were used for pain relief.

Three hours after envenomation he was breathless and developed chest tightness with bilateral rhonchi and fine basal crackles. The oxygen saturation was $90 \%$ on air, suggestive of acute pulmonary oedema with preserved cardiac parameters which is a recognised complication of Hottentotta tamulus envenomation. It is reported as a rare event 3 hours after exposure to the toxin. A bedside ECG revealed diffuse ST segment changes suggestive of an acute cardiac insult, but no radiographic evidence of pulmonary oedema. Cardiac troponin I value of 1.97 (normal range $0-0.15 \mathrm{ng} / \mathrm{ml}$ ) 4 hours after envenomation confirmed myocardial injury.
The patient was managed in the intensive care unit with 81 of oxygen, intravenous frusemide and ipratropium bromide nebulisation. He maintained an $\mathrm{O}_{2}$ saturation of $98 \%$. After 24 hours of envenomation, pulmonary oedema improved, requiring only $2 \mathrm{l}$ of oxygen to maintain a saturation of $98 \%$, and a normal blood pressure and pulse rate. Prazosin hydrochloride was continued with frusemide boluses.

After 24 hours, cardiac troponin I titre was $3.77 \mathrm{ng} /$ $\mathrm{ml}$. A2D echocardiogram revealed myocarditis with severe left ventricular dysfunction (ejection fraction 33\%) and global hypokinesia. A repeated troponin I level on day 3 was $0.96 \mathrm{ng} / \mathrm{ml}$ and chest X-ray was unremarkable. A coronary angiogram and an echocardiogram performed after a month of the incident were normal.

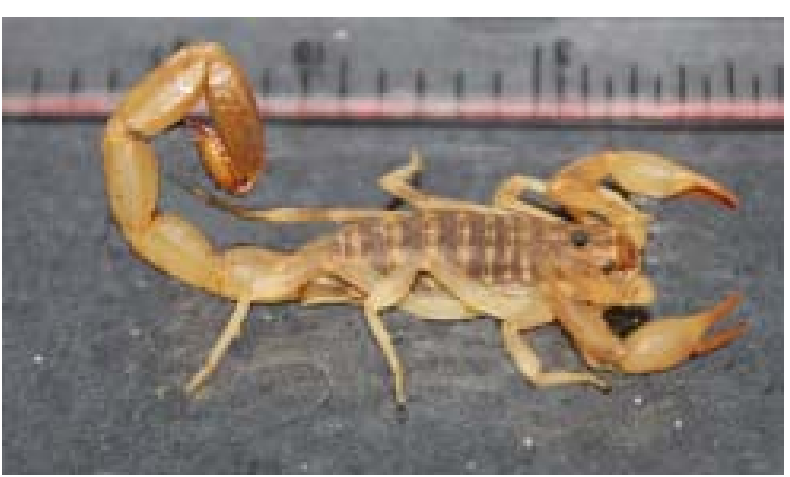

Figure 1. White scorpion of Sri Lanka (Hottentotta tamulus)

\section{Discussion}

Hottentotta tamulus stings observed in the Jaffna peninsula were associated with clinical features of autonomic nervous system overactivity such as changes in pulse rate and blood pressure, sweating, diaphoresis and pulmonary oedema. Myocardial injury with elevated cardiac biomarkers has not been reported in Sri Lanka, although it is a known complication after the 'red scorpion' stings in India [1,2]. Scorpion venom contains a mixture of several low molecular weight basic proteins, neurotoxins,

${ }^{1}$ University Medical Unit, Teaching Hospital, Jaffna, Sri Lanka.

Correspondence: RMUKBR, e-mail: <upathissa@gmail.com>. Received 16 October 2015 and revised version accepted 5 January 2016.

This is an open-access article distributed under the terms of the Creative Commons Attribution License, which permits unrestricted use, distribution, and reproduction in any medium, provided the original author and source are credited. 
nucleotides, amino acids, oligopeptides, cardiotoxins, nephrotoxins, haemolytic toxins, phosphodiesterase, phospholipase A, hyaluroinidase, acetylcholine-esterase, glycosaminoglycans, histamine, serotonin, 5-hydroxyptamine and proteins that inhibit protease, angiotensinase, succinate-dehydrogenese, ribonuclease and 5-nucleotidase. Multiple toxins may be present in the venom of a single species which can produce a synergic effect in the victim [3]. Many other ion channels are also involved, and the term 'autonomic storm' reflects the stimulation of the parasympathetic system.

Although the toxins in Sri Lankan white scorpion venom have not been definitely identified, two mechanisms are thought to contribute to its cardiotoxic properties. Firstly the direct cardiotoxic effect of the venom causing toxic myocarditis by reduction of Na-K-ATPase and adrenergic myocarditis by releasing adrenaline and noradrenaline from neurons, ganglia, and adrenals. The second mechanism is myocardial ischaemia caused by coronary spasm due to release of vasoactive, inflammatory and thrombogenic peptides and amine constituents (histamine, serotonin, bradykinin, leukotrienes and thromboxane) [4]. This acts on the coronary vasculature and induces coronary artery spasm and facilitates platelet aggregation, leading to thrombosis [5]. Prompt treatment with prazosin hydrochloride and supportive care has reduced the morbidity and mortality from scorpion stings in hospitalised patients.

\section{Ethics}

Patient has given informed, written consent for this publication.

\section{Conflicts of interests}

There are no conflicts of interest.

\section{References}

1. Kularatne SA, Dinamithra NP, Sivansuthan S, et al. Clinicoepidemiology of stings and envenoming of Hottentotta tamulus (Scorpions: Buthidae), the Indian red scorpion from Jaffna Peninsula in northern Sri Lanka. Toxicon 2015; 93: 85-9.

2. Bawaskar HS, Bawaskar PH. Scorpion sting: update. $J$ Assoc Physicians India 2012; 60: 46-55.

3. Possani LD, Baltazar B, Delepierre M, et al. Scorpion toxins specific for NA+ channels. Eur J Biochem 1999; 264: 287-300.

4. Rahav G, Weiss AT. Scorpion sting-induced pulmonary edema. Chest 1990; 97: 1478-80.

5. Yang HP, Chen FC, Chen CC, et al. Manifestations mimicking acute myocardial infarction after honeybee sting. Acta Cardiol Sin 2009; 25: 31-5. 